Article

\title{
Two Sides of the Coin: The Link Between Relational Exclusion and Socioeconomic Exclusion
}

\author{
Verónica de Miguel-Luken * and Livia García-Faroldi \\ Department of State Law and Sociology, University of Malaga, Spain; E-Mails: vdmiguel@uma.es (V.D.M.-L.), \\ Igarcia@uma.es (L.G.-F.) \\ * Corresponding author
}

Submitted: 15 May 2021 | Accepted: 10 August 2021 | Published: 15 December 2021

\begin{abstract}
Social capital, derived from the individual embeddedness in a net of personal relationships that gives access to a pool of potential resources, is crucial in understanding how some people experience a higher risk of falling into social exclusion. In this article, we related some compositional and structural factors of egocentered networks to various measures on economic deprivation and social exclusion. We considered different explanatory dimensions: ego's sociodemographic characteristics and ego's social capital. Social capital was measured both in terms of expressive and instrumental support, and took into account network size, strong ties density, and alters' average job prestige, differentiating between inherited and achieved capital, a distinction that has deserved little attention so far. We used data from the Spanish General Social Survey $2013(N=5,094)$, a nationally representative database not applied for similar purposes up to the present. Results show how economic deprivation and social exclusion are associated with ascribed and achieved characteristics, both at the micro level (individual) and the meso level (network). At the micro level, women, immigrants, young people, less-educated people, the unemployed, and those who do not trust others have higher estimated values on the variables with regards to social disadvantage. At the meso level, social exclusion is associated with lower occupational prestige of achieved relationships, fewer contacts for obtaining economic or medical help (but more contacts for childcare) and smaller non-kin core discussion networks. In a familistic society with a limited welfare system, results help to disentangle the level of dependence people have on their own social resources.
\end{abstract}

\section{Keywords}

achieved social capital; deprivation; egocentered networks; inherited social capital; Spanish General Social Survey

\section{Issue}

This article is part of the issue "In Good Company? Personal Relationships, Network Embeddedness, and Social Inclusion" edited by Miranda J. Lubbers (Autonomous University of Barcelona, Spain).

(C) 2021 by the authors; licensee Cogitatio (Lisbon, Portugal). This article is licensed under a Creative Commons Attribution 4.0 International License (CC BY).

\section{Introduction}

The study of poor populations has a long history in sociology, but the association of deprivation with the social networks has received less attention than what should be appropriate, if we take into account that poverty is relational (Lubbers et al., 2020a). Among those authors who have paid attention to the role of networks in explaining poverty and social exclusion, a main focus of research has been social capital. Social capital is derived from the individual embeddedness in a net of personal relationships that gives access to a pool of potential resources (Lin, 1999a, 2000a). Empirical evidence has shown that poor people have networks of restricted range and fewer instrumental resources (Van Groenou \& Van Tilburg, 2003; Wilson, 1987). Both strands of research-social capital and social support-have a long tradition: The social capital literature has been closely related to job-market issues, such as unemployment, earnings or job prestige, while the scholarship on social support has been linked to the study of poverty and social exclusion. In our case, we consider social capital 
from the perspective of the analysis of personal networks (and not from the macro approach grounded on trust in people, institutions, etc.), which understands social support as an implementation of social capital.

In this article, we investigate how individual and network factors are related to poverty and social exclusion. We use data from the Spanish General Social Survey of 2013, a year of profound economic crisis, with high rates of unemployment and a population at risk of poverty and social exclusion. Our article contributes to the literature using a unique, representative Spanish survey, specifically designed to study discussion networks (formed by people with whom important matters are discussed) and social support. This survey was inspired by the American General Social Survey (Burt, 1984). As far as we know, this is the first work that uses these data to analyse how structural factors are linked to social exclusion. Furthermore, we distinguish between inherited resources (through parents, siblings, and other kin present from ego's birth) and acquired resources (all others), a distinction that is normally missing in the literature (Contreras et al., 2019).

The article is structured as follows. After this Introduction, the theoretical framework explains the empirical evidence about how social capital and social support differs between poor people and more economic advantaged sectors. The next section explains the methodology and database, while the fourth shows the main findings. The article finishes with a conclusion and discussion of the results.

\section{Social Networks and Social Capital}

Social networks have received far less attention than neighbourhoods and organizations when studying the causes of poverty (Lubbers et al., 2020a). Nevertheless, poverty is profoundly relational because "it is lived, managed, negotiated and reproduced in relationships with others" (Lubbers et al., 2020a, p. 8).

Among those authors who have paid attention to the role of networks in explaining poverty and social exclusion, a main focus of research has been social capital. This is not casual because as Pichler and Wallace (2009, p. 319) claimed "the formulation of the concept... is heavily influenced by its relationship to the reproduction of inequality." For example, Bourdieu (1986, p. 248) defined social capital as "the aggregate of the actual or potential resources which are linked to possession of a durable network of more or less institutionalised relationships of mutual acquaintance and recognition." On the same line, Lin (1999a, p. 30) defined social capital as "investment and use of embedded resources in social relations for expected returns." The concept implies two conceptualizations: The first emphasizes resources and the second emphasizes locations in a network (Lin, 2000b).

We can find a similar distinction in Wilson's reflection about the urban poor. For the author, this group has networks of restricted range and fewer instrumen- tal resources (Wilson, 1987). Portes' (1998) definition of social capital also highlighted two dimensions-the structural element (the relationships with alters) and the resource element (the number and quality of resources possessed by these alters). As Hurlbert et al. (2008) suggested, Granovetter's (1982) discussion of poverty also echoed this division, because he argued that poor individuals' networks lacked weak ties (structural element) and, therefore, the access to instrumental resources that weak ties enabled.

As $\mathrm{Li}$ et al. (2005) noticed, there is a difference between the approach developed by Bourdieu and Lin, which focused on how social capital benefited individuals, and a second approach developed by Putnam (1993), more interested in how it generated collective goods. This second line of research studies how engagement in civic organizations increases cooperation and trust in others. For example, Li et al. (2005) demonstrated that civic participation generated social trust and that the more advantageous the individual's socio-cultural position was, the more likely they tended to trust others. Although this line of research is interesting, we focus on the first perspective because it is closely related to social exclusion, both at the micro and the macro level.

According to Lin (2000b), social groups have different amounts of social capital due to two phenomena: first, a structural process by which each society provides unequal socioeconomic opportunities to members of different groups defined according to race, gender, religion or other characteristics; second, a general tendency in networking to interact with others who are similar (social homophily) as a result of a selection effect (Mouw, 2003) and the interactions developed in homogeneous social foci (defined as entities around which joint activities of individuals are organised; Feld, 1981). As Lin (2000b, p. 787) argued, "these two principles, when operating in tandem, produce relative differential access by social groups to social capital." Various indicators of social capital have been proved higher in more advantaged status groups that have more heterogeneous networks, with the presence of bridging social capital in contrast with bonding social capital in lower status groups (Campbell et al., 1986; Pichler \& Wallace, 2009; Van Groenou \& Van Tilburg, 2003).

When analysing an individual's social capital, three dimensions have normally been taken into account (Flap, 2002; Lin, 2000a): the presence of alters, the resources of these alters, and the availability of these resources for ego. On the other hand, the outcomes of social capital could be divided into instrumental actions (gaining resources) and expressive actions (maintaining resources, such as gaining emotional support and sharing of sentiments; see Lin, 2000a, pp. 45-46). While expressive outcomes are not a result of access to higher occupational prestige members (Lin, 1999a; Van der Gaag et al., 2008), empirical evidence has suggested that instrumental actions are closely related to access to higher status positions. 
One of the most analysed outcomes of social capital is related to labour market. The literature has demonstrated that job seekers are not necessarily helped by having social contacts per se, but by the resources of these contacts (the socio-economic composition of the network members). For example, Canduela et al. (2015) found that bonding relations (both in the primary and secondary sphere) were not associated with entering employment, but bridging social capital (measured as the availability of someone outside the household to help find a job) was related to it. In their analysis of which factors influenced the decision of youth on entering the labour market or continuing in education, Verhaeghe et al. (2015) analysed how inherited social capital (educational and class positions of the parents) affected children's decision to continue in education or to enter the labour market.

In this field, it is common to study the access and availability to alters in rewarded positions, measured in terms of socioeconomic indexes or through occupational prestige measures. De Graaf and Flap (1988) proved that the occupational prestige of the contact person that helped to find the first job had a significant positive direct effect on respondent's occupational prestige in the Netherlands, although the influence of social resources on earnings was largely indirect. Even if some evidence has been found that social capital adds to human capital for the explanation of the inequalities in socioeconomic status and income (Boxman et al., 1991; Campbell et al., 1986; Shen \& Bian, 2018), some other studies have contested the causality of this relationship, pointing out the selection effects; thus, having friends in high positions makes it easier to reach a good position that, in turn, reinforces socialisation with people of the acquired status (De Graaf \& Flap, 1988; Mouw, 2003). Therefore, we hypothesise:

H1. Higher average job prestige of alters is associated with the access to better jobs and, consequently, with the achievement of ego's better economic positions and lower risk of social exclusion. Although this relationship will hold for both inherited and achieved members of the core discussion network, acquired ties in a meritocratic society are expected to be more relevant.

Granovetter's (1973) theory of the strength of weak ties contended that weak ties provided an important flow of information in contrast to redundant information facilitated by strong ties. Furthermore, actors whose networks can span social layers thanks to weak ties are more likely to be socially mobile, especially if their networks can bridge crucial "structural holes" (Burt, 1992). Lin argued that embeddedness in resource-rich social networks increased the likelihood of receiving useful information even if the person was not actively seeking such information, a phenomenon that the author called "the invisible hand of social capital" (Lin, 2000b, p. 792).
The relevance of weak ties in finding a job has been corroborated in some countries (Boxman et al., 1991; Granovetter, 1973), but not in others (Lin, 1999b; for Spain see also Lubbers et al., 2019; Requena, 1991).

On one hand, Granovetter's theory and later empirical research have pointed to the beneficial impact of weak ties on labour market outputs. On the other hand, Burt's redundancy definition is identical to ego network density (when ties to ego are not taken into account; see also Borgatti, 1997). Thus, we expect:

H2. Merging both ideas, strong ties density has a negative influence on income and social inclusion.

\section{Social Support and Social Exclusion}

One of the benefits of social capital is the achievement of social support, which can be defined as the "emotional, informational, or practical assistance from significant others, such as family members, friends, or co-workers" (Thoits, 2010, p. S46). As explained by Lubbers et al. (2020b), three mechanisms govern the constitution and functioning of personal networks: the social foci, the homophily (partly induced by social foci), and social norms (obligation, reciprocity, autonomy, and equity). Taking into account these aspects, Lubbers et al. (2020b) expected that the support networks of poor people were smaller, resources scarcer, and with norms impeding social support mobilisation. Nevertheless, their qualitative results showed a great variation in network size (some individuals had lost contacts while others frequented new social environments) and in availability of resources, with important help given by acquaintances. Regarding network size and composition of poor households, previous studies (Canduela et al., 2015) found that living alone and lone parenting were more frequent among the poor, they more commonly rented their accommodation and they usually lived in households without another earner.

In their revision of literature on poverty and social networks, Lubbers et al. (2020a) highlighted that a large body of research had shown that poor people used extensive networks of kin and other close relationships. However, kin were not always available or were not even addressed in seeking help if those requesting it considered they were not going to be able to satisfy the norm of reciprocity or they expected to be judged from their lack of autonomy. This reduced presence of family in the safety nets is offset to some extent by the provider role that friends or acquaintances assume in harsh situations (Gazso et al., 2016; Grau Rebollo et al., 2019; Lubbers et al., 2020b). Yet some scholars have warned about this "myth of survival" (González de la Rocha, 2007) because some findings based on large-scale surveys have shown that poor people who most need informal support are the least likely to have it (for the European context see Böhnke, 2008; for the American one see Harknett \& Hartnett, 2011). The network disadvantage reported in 
this body of research is a result of both lower network access (which depends on the size and composition of support networks) and network returns (the poor may have similar access but obtain fewer benefits from their networks, according to Pedulla \& Pager, 2019). In this line of thought, some researchers have drawn attention to the insufficient institutional coverage of the neo-liberal (Gazso et al., 2016) or the Mediterranean (Lubbers et al., 2020b) welfare systems, which are based on the questionable idea that family is the primary source of support.

In other aspects, empirical evidence has also shown mixed results about the association between poverty and social support networks. On the one hand, some quantitative studies (both cross-sectional and longitudinal) did not find that networks of the poor (particularly contacts to family and close friends) were reduced (Böhnke \& Link, 2017; Canduela et al., 2015; Dahl et al., 2008; Letki \& Mierina, 2015). These authors emphasised that other variables and not poverty explained patterns of sociability, such as labour market status or ethnicity (Dahl et al., 2008), or life events such as bad health, advancing age or the birth of a child (Böhnke \& Link, 2017). On the other hand, some qualitative studies have focused on how entry into poverty means a reduction or change in social support networks (Boon \& Farnsworth, 2011; Gazso et al., 2016; Lubbers et al., 2020b). Furthermore, these networks are smaller than those of the more affluent and their members comprise low-income individuals. Stack (1974) and Adler de Lomnitz (1977) showed that poor individuals developed and maintained elaborate exchange networks consisting primarily of strong ties (particularly kin). In their comparison of poor urbanites in the USA with the middleclass population, Hurlbert et al. (2008) found greater distinctiveness on the resource element of network capital than on the structural element (restricted geographic range, density, diversity, size, and voluntary organisation integration). Restricted network range constrains access to instrumental resources and emotional support in general (Boon \& Farnsworth, 2011; Lubbers et al., 2019), and plays an important role in explaining the lack of resources in the networks of the poor (Hurlbert et al., 2008). Nevertheless, institutional and cultural contexts have to be taken into account. As Letki and Mierina (2015) demonstrated with their international comparison of 21 countries, while the poor in the non-postcommunist countries had smaller friendship and organisational networks, in postcommunist countries friendship networks were significantly larger than those of the wealthier people, suggesting that they maintained ties in order to gain access to the needed help.

As argued by Böhnke (2008) and Böhnke and Link (2017), two competing hypotheses can be distinguished regarding the association between poverty and social integration: while the thesis of compensation assumes that solidarity will increase and networks will become more tightly knit in the event of material disadvantage, the thesis of accumulation expects that economic disad- vantage results in a feeble social network where social contacts are focused on the family. Thus, network size is important:

H3. The larger the expressive and instrumental networks, the broader the options people have to rely on others, to obtain assistance from them and, thus, to escape deprivation: Particularly, with regards to instrumental support, larger networks are expected to be related to better achievement $(\mathrm{H} 3 \mathrm{~A})$; regarding discussion networks, even if the relationship is expected to be similar to that for the instrumental support (the bigger the better), given the universal provider role associated to kin in a familistic society, the differences in ego's economic and social advantage will be mainly due to the size of non-kin core discussion network (H3B).

Although at the micro level informal networks could help in case of economic necessity, at the macro level they may produce cumulative disadvantage and amplify social inequality. Granovetter (1982, pp. 116-117) arrived to a similar conclusion when he suggested that "the heavy concentration of social energy in strong ties has the impact of fragmenting communities of the poor into encapsulated networks with poor connections between these units....This may be one more factor that makes poverty self-perpetuating." At the macro level, as Lin warned (2000a, p. 96), "inequalities in social capital explain the framework for inequalities in social stratification."

As pointed out by Harknett and Hartnett (2011), the causal ordering in the link between personal disadvantages and personal safety nets is unresolved. Theory and prior research suggested that relationships were usually bidirectional and self-reinforcing. Personal disadvantages are likely to interfere with support relationships, and personal safety-net deficits, in turn, are likely to reinforce and entrench personal disadvantages (DiMaggio \& Garip, 2012). In this article, we analyse the impact of social exclusion on other aspects of exclusion, the economic situation being the most important one.

In this article, we analyse the role of social networks in explaining poverty and social exclusion in Spain. This country has a Mediterranean welfare system in which the family assumes the primary caregiver role and social policies are limited. Furthermore, Spain ranks as one of the European countries with highest inequality and the economic crisis (2008-2015) exacerbated these inequalities. According to the EU-SILC data, the Gini coefficient of equivalised disposable income for 2013 (the year of the data we analyse) was $33.7 \%$ (only Latvia, Lithuania, Romania, and Portugal surpassed Spain) and it increased to 34.7 in 2014. Spain was one of the European countries where the impact of the economic crisis in the labour market was higher (the unemployment rate was $26 \%$ in 2013) and, consequently, poverty increased during that period (from $19.8 \%$ of the population at risk of poverty 
and social exclusion in 2008 to $22.2 \%$ in 2014 , according to data from the National Institute of Statistics). Taking into account these features of the country, it is expected that social capital is unevenly distributed among the Spanish population and that less advantaged groups lack both emotional and instrumental social support.

\section{Methodology}

\subsection{Data}

We used data from the Spanish General Social Survey of 2013, which replicated the American General Social Survey of 1985 (Burt, 1984) and was especially focused on the collection of egocentered data. The questionnaire inquired first about the number of people with whom important matters had been discussed during the previous six months (core discussion network). If the respondent named more than five confidants, the first elicited five persons were selected for the next sections. Subsequently, ties between every pair of alters were collected in two ways: whether the two alters knew each other and whether they had a close relationship (strong ties). Finally, a battery of name interpreters was added, allowing data on many alters' characteristics to be gathered, although the current analysis only includes job prestige and type of relationship. The core discussion network section of the questionnaire was followed by some resource generator items, for which only the number of available alters for each proposed situation and the relation with the most important alter were collected.

The survey was nationally representative, reaching a total sample of $\mathrm{N}=5,094$ although we selected only people who were the household breadwinner, whose partner was the household breadwinner, or both $(n=4,118)$. In this way, we intended to avoid young people still dependent on their parents. Information on family income was available for $n=3,309$ of those respondents.

\subsection{Dependent Variables}

We propose an approach to social exclusion from three different angles. The first one is through the household equivalised net income. By net income, we mean income after taxes. Since net income was collected at intervals, we used the average value of each interval.

For the second dependent variable (household equivalised net income adjusted by housing expenditures), the share of the income estimated to pay the rent or the mortgage was considered (data were obtained for each Spanish province from national housing appraisal and real estate companies), resulting in the total amount for net income, after housing expenditure was discounted. If an interviewee, for example, answered a net family income between 3,001€ and 4,500€ and her housing expenditure was $25 \%$ of the family income, the average value of 3750.5 was multiplied by $(1-0.25=0.75)$. It must be taken into consideration that in Spain rents are nor- mally higher than mortgages, so paying for a property impoverishes people less than paying for a rent.

The two variables were equivalised according to household composition and members were made equivalent by weighting each according to their age: 1 for the first adult, 0.5 for the remaining adults and cohabitants over 13 , and 0.3 for each child under 14 . This is the modified OECD equivalence scale to adjust for household size, previously used by other authors that have analysed poverty, such as Böhnke and Link (2017). This scale is also applied by the Spanish National Institute of Statistics. Then results were standardised (Min-Max normalisation) so the maximum was set to 1 and the minimum to 0 (highest economic deprivation).

Finally, other dimensions that have been previously proven to be related to social exclusion (Barnes, 2005; Böhnke \& Link, 2017; Canduela et al., 2015; European Commission, 2004; Houston \& Sissons, 2012; Pichler \& Wallace, 2009) were considered to create a new index. These indicators were as follows: health (weighted 0: very good, 0.25: good, 0.5: normal, 0.75: poor, and 1: very poor), participation in any of the eleven types of associations and organisations included in the questionnaire ( 0 : yes, $1:$ no), voted in the last general elections (0: yes, 1: no), received basic assistance from NGOs (such as food, clothes or money) in the past 12 months (up to four types of help were asked about from 0: no assistance at all though 1: all types received), and housing tenure (0: property, totally paid for, 0.75: property, paying for a mortgage, and 1: rent). The values for those variables were summed up and divided by five, and the result was assigned a $50 \%$ weighting. The remaining $50 \%$ was for the standardised household equivalised net income. The final index was the sum of both. Values ranged from 0 to 1 , higher values meaning higher social exclusion. Weightings were changed in order to make some robustness analysis (results upon request) and conclusions were basically the same as for the models included in this article, where we have prioritised the relevance of income in the construction of the index.

Despite the fact that we have considered deprivation from the viewpoint of the household, in line with a strong current in poverty research and provided that inequality is normally increased when the perspective is on the family unit instead of the individual (Domínguez Domínguez \& Martín Caraballo, 2006), our independent variables were measured at the individual level. The assumed extended homogamy in couples and overlapping of partners' instrumental support networks make our approach feasible. Nevertheless, the same explanatory models were run for the dependent variables built from the individual income and results were quite similar (results upon request).

\subsection{Independent Variables}

Sociodemographic variables were added as control variables: sex, place of birth (Spain, abroad), age-group, 
academic attainment, employment status, living with a partner, number of children under 16 at home, and degree of urbanisation. Given that the Spanish General Social Survey included items to measure personality traits (the so-called "Big Five," see Goldberg, 1990) that have been proved to affect the creation and maintenance of social networks (Requena \& Ayuso, 2018; Staiano et al., 2012; Swickert et al., 2002), we checked them as control variables. Interpersonal trust ("it is easy for me to trust people") and conscientiousness ("I do the things that must be done conscientiously"), both dichotomised to 1 (totally agree, mostly agree) and 0 (unclear, mostly disagree, totally disagree) were significant at some point. Some other psychological variables were finally omitted due to their lack of statistical significance: neuroticism, openness, and extraversion.

Discussion and instrumental network sizes were considered. For expressive support, total discussion network size and core discussion network size were tested. The latter was divided into kin and non-kin since characteristics of core alters were collected. The maximum size for the core network was limited to five because of the questionnaire's design. The idea was to distinguish between non-chosen or ascribed ties (kin) and chosen ties (all others, including the partner). Regarding the resource generator questions for instrumental support, the size of the different proposed scenarios was inquired about, but no characteristics were collected for the alters. Although five different resources were included in the questionnaire, just three proved significant in the models: potential available help to take care of the children (asked even in cases in which respondent has no children), potential available alters to ask for economic help, and potential alters who would accompany ego to the doctor or to the hospital. The other two (help to solve an administrative paperwork and help in case of illness) were excluded from the models.

Average alters' prestige (network composition) was studied. Subjective prestige for each occupation was obtained from a nationally representative survey of the Spanish population (study number 3004-2014 carried out by the Centre for Sociological Research). This information was used to calculate the range of alters' prestige, the maximum alters' prestige and the average alters' prestige (Van der Gaag et al., 2008), distinguishing between achieved (friends, acquaintances, partner, etc.) and ascribed or inherited associates (father/ mother, brother/sister, and other kin known from birth). Although the three measures-prestige's range, average, and maximum-were significant in the models, the average was the variable with the strongest predictive power so the other two were finally omitted.

The questionnaire asked whether every pair of alters knew each other or not and whether the relationship between them was close (strong-ties density). Based on the structural holes' theory (Burt, 1992), we defined density as the number of observed ties between alters with a close relationship (I) divided by the total number of possi- ble ties $n \times(n-1) / 2$, thus: $2 / /(n \times(n-1))$, if $n>1$. Thus, this measure is not about alters with whom ego has a strong tie but about strong ties between alters.

\subsection{Analytical Approach}

Linear regression models were run to estimate the dependent variables, which were considered as continuous in Stata 14. Outliers and cases with an extremely high leverage were omitted from the analysis using the Cook indicator. Data were weighted for the descriptive results and the models.

In order to better address the hypotheses, in Table 1 we first show the estimated coefficients for the three variables related to the size and the structure of the discussion network: total number of alters with whom personal matters had been discussed in the previous six months (discussion network size, no limitation), kin and non-kin core discussion network sizes (the sum of both limited to 5 alters), and density of strong ties between every pair of elicited alters (again, limited to 5 alters). The three of them were correlated, so we checked them separately in different models. In these first models, no information about alters' occupational prestige was added. In Table 2, the complete models for the three dependent variables are presented. As for the information on discussion network, we just kept the sizes of kin and non-kin core discussion networks (density was no longer significant). For the sake of clarity, we do not include the estimators for the control variables, nor the instrumental support network size (from the resource generators) in Table 1, which are consistent with those observed in Table 2.

\section{Results}

Discussion network size matters (Table 1). In general, the larger the discussion network, the higher both estimated household incomes. Still, when core discussion network size is disaggregated into kin and non-kin, this positive association is just significant for non-kin. As for the index of social exclusion, for which the economic dimension is linked to other factors, all estimators on size are significant and point to the same direction: Broader support is linked to situations that are more favourable. The magnitudes of the values indicate the stronger intensity of the relationship of these variables with the index on exclusion. Density of strong ties among alters is barely illustrative in understanding poverty and exclusion even if the signs of the coefficients are consistent for the three models and suggest the expected relationship: bonding social capital seems to be detrimental in the terms considered.

Table 2 presents the complete models for the three dependent variables, with alters' occupational prestige measures included. In all the models, being a woman and being foreign-born is negatively linked to equivalised family income and positively linked to exclusion (in the case of women, these results are presumably affected 
Table 1. Linear regression beta coefficients for household equivalised net income, household equivalised net income adjusted by housing expenditures, and social exclusion.

\begin{tabular}{lccc}
\hline & $\begin{array}{c}\text { core discussion network size: } \\
\text { kin } \\
\text { sizen-kin }\end{array}$ & $\begin{array}{c}\text { censity strong ties } \\
\text { among alters }\end{array}$ \\
\hline household equivalised net income & $0.038^{*}$ & 0.020 & $-0.029+$ \\
& & $0.042^{*}$ & -0.023 \\
household equivalised net income & $0.039^{*}$ & 0.021 & $0.050^{* *}$ \\
adjusted by housing expenditures & & $-0.038^{*}$ & $0.039^{*}$ \\
Social exclusion & $-0.058^{* *}$ & $-0.098^{* * *}$ & \\
\end{tabular}

Notes: ${ }^{* *} p<0.001,{ }^{* *} p<0.01,{ }^{*} p<0.05,+p<0.10$; models are controlled for sex, age group, nativity, academic level, labour situation, partnership, number of children under 16 in the household, degree of urbanisation, psychological features, and size of instrumental networks.

by those households in which the woman is the only breadwinner). In relation to this, living with an intimate partner improves the economic condition of the family and prevents social exclusion, but the number of children under 16 at home aggravates the situation whichever dependent variable is observed.

According to age, the only group with a clear significant negative effect on income when the effort of paying for housing is not adjusted is 45-59 (Model 1), probably because it clusters people with children above 16 and still belonging to the household. When housing expenses are adjusted (Model 2), respondents between 60 and 74 have higher estimated family income, very likely due to the overrepresentation of houses that are owned and completely paid for in this age group. The relationship with age is not perfectly linear for the index on social exclusion (Model 3), but it is this group again (60-74) that seems to enjoy the best position whilst the youngest (up to 29) has the highest social exclusion estimated value. Two factors may help interpret these findings: (a) Spain is a country with high level of youth unemployment (unemployment rates in Spain in 2013 were $\mathbf{7 4 . 0 \%}$ for the age group $16-19,51.8 \%$ for $20-24$, and $33.3 \%$ for 25-29), and (b) Spain is a country where people leave their parents' home comparatively very late. We have kept the calculations only for the people who are the main breadwinner and/or whose partner is the main breadwinner; therefore, young people that remain in the sample are presumably not dependent on their parents anymore. It seems that they are more at risk of being in a vulnerable situation: renters with low salaries, and individuals more unconnected to the assistance of NGOs and to political participation. The following age group is not far away from them.

As the academic level rises, the expected value for equivalised family incomes increases as well (Models 1 and 2, Table 2), and the estimated social exclusion diminishes (Model 3, Table 2). Concerning the labour situation, all categories have negative effects on income and a positive effect on social exclusion as compared to employed people, the unemployed being the group with the lowest estimated incomes and the highest estimated value for exclusion. Regarding psychological features, trusting others is positively associated with the family economy and negatively with social exclusion. The coefficient for considering oneself as conscientious is only slightly significant for the third model (Table 2), this being a trait that apparently favours inclusion.

Regarding instrumental support, once we control for socio-demographic and psychological variables, the fact of having a larger available network for taking care of the children is related to a reduction in the values for equivalised family income and for housing adjusted equivalised family income (Models 1 and 2, Table 2). This is the only situation where the sign of the estimator on size is not as predicted. The other two items proposed as resource generators, number of associates who could provide economic help and number of associates who could go with ego to the doctor or to the hospital, point to the expected direction: Larger networks are associated with better outcomes in all three dependent variables.

The core discussion network variables on size (kin and non-kin networks) lose their significance as information about alters' prestige is added to the Models for the equivalised household income and for the housing adjusted equivalised household income (Models 1 and 2, Table 2), suggesting that whoever the person is connected to is more important than how many connections this person has. Only non-kin discussion network size remains negatively related to social exclusion (Model 3, Table 2), giving strength to the idea that the number of relatives with whom important matters are discussed does not differentiate between population's performance as much as the number of available non-kin for expressive support.

Consistently, and even if both inherited meanprestige and achieved mean prestige are positively related to better outcomes (Table 2), it is achieved prestige that has a stronger association with equivalised 
Table 2. Linear regression models (beta coefficients).

\begin{tabular}{|c|c|c|c|}
\hline & $\begin{array}{c}\text { Model } 1 \\
\text { family equivalised } \\
\text { net income }\end{array}$ & $\begin{array}{l}\text { Model } 2 \\
\text { household equivalised net income } \\
\text { adjusted by housing expenditures }\end{array}$ & $\begin{array}{c}\text { Model } 3 \\
\text { social exclusion }\end{array}$ \\
\hline \multicolumn{4}{|l|}{ sex } \\
\hline men & & & \\
\hline women & $-0.070 * * *$ & $-0.073 * * *$ & $.115^{* * *}$ \\
\hline \multicolumn{4}{|l|}{ nativity } \\
\hline native & & & \\
\hline foreign-born & $-0.155^{* * *}$ & $-0.188 * * *$ & $.351 * * *$ \\
\hline \multicolumn{4}{|l|}{ age group } \\
\hline $18-29$ & & & \\
\hline $30-44$ & -0.018 & 0.003 & -.029 \\
\hline $45-59$ & $-0.134 * * *$ & -0.051 & $-.092 * *$ \\
\hline $60-74$ & -0.011 & $0.086 *$ & $-.235 * * *$ \\
\hline $75+$ & -0.014 & 0.043 & $-.154 * * *$ \\
\hline \multicolumn{4}{|l|}{ academic level } \\
\hline no completed studies & & & \\
\hline primary & $0.045^{*}$ & 0.041 & $-.086 * *$ \\
\hline secondary & $0.092 * *$ & $0.119 * *$ & $-.186 * * *$ \\
\hline non-compulsory secondary & $0.251^{* * *}$ & $0.260 * * *$ & $-.291 * * *$ \\
\hline university & $0.458 * * *$ & $0.466 * * *$ & $-.474 * * *$ \\
\hline \multicolumn{4}{|l|}{ employment status } \\
\hline employed & & & \\
\hline retiree & $-0.173 * * *$ & $-0.134 * * *$ & $.109 * * *$ \\
\hline unemployed & $-0.269 * * *$ & $-0.244 * * *$ & $.154 * * *$ \\
\hline other inactive & $-0.180 * * *$ & $-0.159 * * *$ & $.080 * * *$ \\
\hline \multicolumn{4}{|l|}{ partnership } \\
\hline living with a partner & $0.255^{* * *}$ & $0.268 * * *$ & $-.169 * * *$ \\
\hline $\begin{array}{l}\text { number of children }<16 \text { in } \mathrm{hh} \\
\text { degree of urbanisation }\end{array}$ & $-0.212^{* * *}$ & $-0.203^{* * *}$ & $0.064^{* *}$ \\
\hline $10,001-400,000$ inhab. & 0.022 & 0.015 & .019 \\
\hline urban: $>400,000$ inhab & 0.023 & 0.008 & .005 \\
\hline \multicolumn{4}{|l|}{ psychological features } \\
\hline trust in people & $0.056 * * *$ & $0.047 * *$ & $-.096 * * *$ \\
\hline conscientious & 0.018 & 0.012 & $-.027+$ \\
\hline \multicolumn{4}{|l|}{ core discussion network size } \\
\hline kin & 0.004 & 0.004 & -.014 \\
\hline non-kin & 0.016 & 0.022 & $-.069 * *$ \\
\hline \multicolumn{4}{|l|}{ instrumental network size } \\
\hline childcare & $-0.069 * *$ & $-0.088 * * *$ & $.057^{*}$ \\
\hline economic help & $0.049 * *$ & $0.053^{* *}$ & $-.055^{* *}$ \\
\hline accompany to the doctor & $0.036+$ & $0.045^{*}$ & $-.057 * *$ \\
\hline \multicolumn{4}{|l|}{ network composition } \\
\hline mean prestige inherited & $0.050 * *$ & $0.040^{*}$ & -.018 \\
\hline mean prestige achieved & $0.119 * * *$ & $0.136 * * *$ & $-.133 * * *$ \\
\hline observations (n) & 2,292 & 2,116 & 2,090 \\
\hline R-squared & 0.487 & 0.457 & 0.459 \\
\hline
\end{tabular}

Note: ${ }^{* * *} p<0.001, * * p<0.01, * p<0.05,+p<0.10$.

incomes and social exclusion. As stated above, these predictors about the composition of the core discussion network practically cancel out the effects of size shown in Table 1.

\section{Discussion and Conclusion}

This article contributes to the existing literature through the discussion of the differential relationships between achieved and inherited social capital and various 
measures of economic and social disadvantage, which has deserved little attention so far (Contreras et al., 2019). Furthermore, the research distinguishes between the size of discussion and instrumental networks, drawing on a nationally representative database not used for similar purposes up to the present.

Although our focus was on the influence of network indicators, and some of them have been proven to be significant in understanding deprivation and social exclusion, we have to admit that individual factors are more determinant predictors. Being unemployed, female, foreign-born, and having children under 16 relates to worse results, whilst higher academic level, the fact of living with a partner and being trustful and conscientious have a positive impact, consistent with previous findings (Böhnke, 2008; European Commission, 2004; Lubbers et al., 2020a; Van Groenou \& Van Tilburg, 2003).

Regarding $\mathrm{H} 3 \mathrm{~A}$ and $\mathrm{H} 3 \mathrm{~B}$, concerning the link of network size with material deprivation, findings partially confirm H3A. Having a larger instrumental network (measured in terms of economic help or company to the doctor) is positively related to higher income and less social exclusion. On the contrary, having a large network for childcare has the opposite effect. This could be due to two reasons. First, more geographically mobile people in Spain are often from upper employment status, so it could be that wealthier people more often do not have people close to them to care for their children and, furthermore, they can afford formal paid support. Second, previous studies found that the norm of autonomy (independence from household unit) has exemptions in the case of caring for young children (Lubbers et al., 2020b) and that having children in a family increases individual's recourse to family members in emergency situations (Böhnke, 2008).

H3B is again partially confirmed because the size of the discussion network is only significant (the larger the network, the better) when alters' prestige is not taken into account. Instrumental support seems more relevant for a higher position than expressive support, consistent with previous research (Lin, 1999a; Van der Gaag et al., 2008). Furthermore, we have found that non-kin expressive support is more frequent in more socioeconomicallyadvantaged people and kin networks are similar across different layers of the society (as in Van Groenou \& Van Tilburg, 2003). Previous research found that poor people tended to exchange support mostly with strong ties (basically relatives; see Adler de Lomnitz, 1977; Stack, 1974), and that especially in Mediterranean (and also postcommunist) countries they appealed to family more often in seeking help (Böhnke, 2008). However, our results are more in line with those of other authors that stressed the fact that the differences between wealthier and disadvantaged people were mainly found in the sorts of available resources, but not that much in the number of available alters (Hurlbert et al., 2008; Pedulla \& Pager, 2019). As Böhnke (2008) suggested, in Mediterranean countries poor people are better socially integrated than in the rest of Europe because family solidarity is more widespread.

The general picture we obtain for Spain is that inherited social capital is less crucial in determining social status (in the proposed terms) than achieved social capital. Higher average job prestige of alters is associated with better economic positions and lower risk of social exclusion, as expected by $\mathrm{H} 1$, but findings show that achieved social capital is more important than inherited capital (in fact, ascribed is not significant when analysing social exclusion, and its significance diminishes when taking into account housing expenses). These results are expected in a society that, despite its strong economic inequality, is also characterised by the possibility of social mobility. According to the World Economic Forum (2020), four generations are necessary for a low-income family to reach median income, a figure similar to Australia, Canada, and Japan, and below some other countries in the OECD context, such as the USA, UK, France or Germany.

Finally, $\mathrm{H} 2$ is not clearly confirmed: Density of strong ties in discussion networks is very weakly related to economic deprivation (household equivalised net income) and slightly more related to social exclusion, but only if prestige is not accounted for in the models. Once average alters' prestige is controlled for, density is not significant anymore (results not shown). This unexpected result could be partially due to the limited number of alters for whom the survey provided relational information (a maximum of five). In any case, there is no significant evidence that bonding capital and the lack of structural holes (Burt, 1992) are related to individual performance.

Our research has some limitations. The first and most important one, the restriction on the number of alters of the core discussion network already mentioned affected the sizes of our kin and non-kin discussion networks and measures on job prestige. On the other hand, although the association between social capital and several labour market outcomes are well established, the causality could be questioned (Harknett \& Hartnett, 2011; Mouw, 2003, 2006). As Verhaeghe et al. (2015, p. 176) put it: "Do social contacts' resources affect the occupational attainment or do privileged socioeconomic positions allow to become friends with people with more resources?" Longitudinal data are convenient in answering this question properly but even if our study is crosssectional, the use of variables related to "inherited capital" helped disentangle the causality between social capital and socioeconomic situation.

\section{Acknowledgments}

This research is based on the results of project FEDER Andalusia 2014-2020, funded by the European Union (UMA18-FEDERJA-103), on research funded by the Ministry of Science and Innovation (PID2020-115673RB100), and research funded by the BBVA Foundation (35_2019). 


\section{Conflict of Interests}

The authors declare no conflict of interests.

\section{References}

Adler de Lomnitz, L. (1977). Networks and marginality. Academic Press.

Barnes, M. (2005). Social exclusion in Great Britain. An empirical investigation and comparison with the EU. Ashgate. vBöhnke, P. (2008). Are the poor socially integrated? The link between poverty and social support in different welfare regimes. Journal of European Social Policy, 18(2), 133-150.

Böhnke, P., \& Link, S. (2017). Poverty and the dynamics of social networks: Am analysis of German Panel Data. European Sociological Review, 33(4), 615-632.

Boon, N., \& Farnsworth, J. (2011). Social exclusion and poverty: Translating social capital into accessible resources. Social Policy \& Administration, 45(5), 507-524.

Borgatti, S. P. (1997). Structural holes: Unpacking Burt's redundancy measures. Connections, 20(1), 35-38.

Bourdieu, P. (1986). The forms of capital. In J. Westport (Ed.), Handbook of theory and research for the sociology of education (pp. 214-258). Greenwood Press.

Boxman, E. A. W., De Graaf, P. M., \& Flap, H. D. (1991). The impact of social and human capital on the income attainment of Dutch managers. Social Networks, 13, 51-73.

Burt, R. S. (1984). Network items and the General Social Survey. Social Networks, 6, 293-339.

Burt, R. S. (1992). Structural holes: The social structure of competition. Harvard University Press.

Campbell, K. E., Marsden, P. V., \& Hurlbert, J. S. (1986). Social resources and socioeconomic status. Social Networks, 8, 97-117.

Canduela, J., Lindsay, C., Raeside, R., \& Graham, H. (2015). Employability, poverty and the spheres of sociability-Evidence from the British Household Panel Survey. Social Policy \& Administration, 49(5), 571-592.

Contreras, D., Otero, G., Díaz, J. D., \& Suárez, N. (2019). Inequality in social capital in Chile: Assessing the importance of network size and contacts' occupational prestige on status attainment. Social Networks, 58, 59-77.

Dahl, E., Fløtten, T., \& Lorentzen, T. (2008). Poverty dynamics and social exclusion: An analysis of Norwegian Panel Data. Journal of Social Policy, 27(2), 231-249.

De Graaf, N. D., \& Flap, H. D. (1988). "With a little help from my friends": Social resources as an explanation of occupational status and income in West Germany, the Netherlands and the United States. Social Forces, 67(2), 452-472.

DiMaggio, P., \& Garip, F. (2012). Network effects and social inequality. Annual Review of Sociology, 38, 93-118.
Domínguez Domínguez, J., \& Martín Caraballo, A. M. (2006). Medición de la pobreza: Una revisión de los principales indicadores [Poverty measurement: A review of the main indicators]. Revista de Métodos Cuantitativos para la Economía y la Empresa, 2, 27-66.

European Commission. (2004). Joint report on social inclusion. Directorate-General of Employment and Social Affairs.

Feld, S. L. (1981). The focused organization of social ties. American Journal of Sociology, 86(5), 1015-1035.

Flap, H. (2002). No man is an island. In E. Lazega \& O. Fevereau (Eds.), Conventions and structures (pp. 29-59). University Press.

Gazso, A., McDaniel, S., \& Waldron, I. (2016). Networks of social support to manage poverty: More changeable than durable. Journal of Poverty, 20(4), 441-463.

Goldberg, L. R. (1990). An alternative "description of personality": The Big-Five factor structure. Journal of Personality and Social Psychology, 59, 1216-1229.

González de la Rocha, M. (2007). The construction of the myth of survival. Development and Change, 38(1), 45-66.

Granovetter, M. (1973). The strength of weak ties. American Journal of Sociology, 78(6), 1360-1380.

Granovetter, M. S. (1982). The strength of weak ties: A network theory revisited. In P. V. Marsden \& N. Lin. (Eds.), Social Structure and Network Analysis (pp. 105-130). SAGE.

Grau Rebollo, J., Escribano Castaño, P., ValenzuelaGarcía, H., \& Lubbers, M. J. (2019). Charities as symbolic families: Ethnographic evidence from Spain. Journal of Organizational Ethnography, 8(1), 25-41.

Harknett, K. S., \& Hartnett, C. S. (2011). Who lacks support and why? An examination of mothers' personal safety nets. Journal of Marriage and Family, 73(4), 861-875.

Houston, D., \& Sissons, P. (2012). The changing geography of privately rented housing in England and Wales. Urban Studies, 36(3), 795-819.

Hurlbert, J. S., Beggs, J. J., \& Haines, V. A. (2008). Distinctiveness and disadvantage among the urban poor. Is low network capital really the problem? In R. Hsung, N. Lin, \& R. L. Breiger (Eds.), Contexts of social capital: Social networks in markets, communities and families (pp. 244-273). Routledge.

Letki, N., \& Mierina, I. (2015). Getting support in polarized societies: Income, social networks, and socioeconomic context. Social Science Research, 49, 217-233.

Li, Y., Pickles, A., \& Savage, M. (2005). Social capital and social trust in Britain. European Sociological Review, 21(2), 109-123.

Lin, N. (1999a). Building a network theory of social capital. Connections, 22, 28-51.

Lin, N. (1999b). Social networks and status attainment. Annual Review of Sociology, 25, 467-487.

Lin, N. (2000a). Social capital: A theory of structure and action. Cambridge University Press. 
Lin, N. (2000b). Inequality in social capital. Contemporary Sociology, 29(6), 785-795.

Lubbers, M. J., Molina, J. L., \& Valenzuela-García, H. (2019). When networks speak volumes: Variation in the size of broader acquaintanceship networks. Social Networks, 56, 55-69.

Lubbers, M. J., Small, M. L., \& Valenzuela García, H. (2020a). Do networks help people to manage poverty? Perspectives from the field. The Annals of the American Academy, 689, 7-25.

Lubbers, M. J., Valenzuela García, H., Escribano Castaño, P., Molina, J. L., Casellas, A., \& Grau Rebollo, J. (2020b). Relationships stretched thin: Social support mobilization in poverty. The Annals of the American Academy, 689, 65-88.

Mouw, T. (2003). Social capital and finding a job: Do contacts matter? American Sociological Review, 68(6), 868-898.

Mouw, T. (2006). Estimating the causal effect of social capital: A review of recent research. Annual Review of Sociology, 32, 79-102.

Pedulla, D., \& Pager, D. (2019). Race and networks in the job search process. American Sociological Review, 84(6), 983-1012.

Pichler, F., \& Wallace, C. (2009). Social capital and social class in Europe: The role of social networks in social stratification. European Sociological Review, 25(3), 319-332.

Portes, A. (1998). Social capital: Its origins and applications in modern sociology. Annual Review of Sociology, 24, 1-24.

Putnam, R. D. (1993). Making democracy work: Civic traditions in modern Italy. Princeton University Press.

Requena, F. (1991). Redes sociales y mercado de trabajo [Social networks and labour market]. Centro de Investigaciones Sociológicas.

Requena, F., \& Ayuso, L. (2018). Individualism or complementarity? The effect of digital personal networks on face-to-face personal networks. Information, Com- munication \& Society, 22(3), 1-15.

Shen, J., \& Bian, Y. (2018). The causal effect of social capital on income: A new analytic strategy. Social Networks, 54, 82-90.

Stack, C. B. (1974). All our kin: Strategies for survival in a Black community. Harper and Row.

Staiano, J., Lepri, B., Aharony, N., Pianesi, F., Sebe, N., \& Pentland, A. (2012). "Friends don't lie"-Inferring personality traits from social network structure. In UbiComp '12: Proceedings of the 2012 ACM conference on ubiquitous computing (pp. 321-330). Association for Computing Machinery.

Swickert, R. J., Hittner, J. B., Harris, J. L., \& Herring, J. A. (2002). Relationships among Internet use, personality, and social support. Computers in Human Behavior, 18(4), 437-451.

Thoits, P. A. (2010). Stress and health: Major findings and policy implications. Journal of Health and Social Behavior, 51, S41-S53.

Van der Gaag, M., Snijders, T. A. B., \& Flap, H. D. (2008). Position generator measures and their relationship to other social capital measures 1. In N. Lin \& B. Erickson (Eds.), Social capital: An international research program (pp. 27-48). Oxford University Press.

Van Groenou, M. I. B., \& Van Tilburg, T. (2003). Network size and support in old age: Differentials by socioeconomic status in childhood and adulthood. Ageing \& Society, 23, 625-645.

Verhaeghe, P.-P., Van der Bracht, K., \& Van de Putte, B. (2015). Inequalities in social capital and their longitudinal effects on the labour market entry. Social Networks, 40, 174-184.

Wilson, W. J. (1987). The truly disadvantaged: The inner city, the underclass, and public policy. University of Chicago Press.

World Economic Forum. (2020). The global social mobility report 2020. http://www3.weforum.org/docs/ Global_Social_Mobility_Report.pdf

\section{About the Authors}

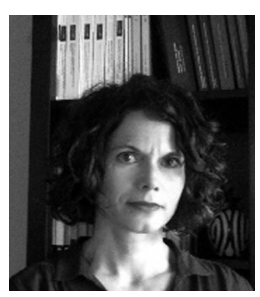

Verónica de Miguel-Luken is associate professor of sociology at the University of Malaga (Spain). Her topics of interest are related to migration processes, both internal and external, family, and social capital. Methodologically, she is mostly focused on social research analysis and its applications to different sociological fields. She has published in international journals such as Social Networks, Social Indicators Research, Social Policy \& Administration, and The Annals of the American Academy of Political and Social Sciences.

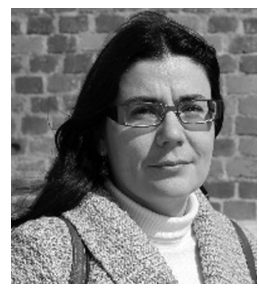

Livia García-Faroldi is associate professor of sociology at the University of Malaga (Spain). She is interested in political identities, welfare states, and sociology of the family. She has published in international journals such as Social Indicators Research (2015), Social Policy \& Administration (2017, together with de Miguel-Luken and Ayuso), International Migration (2017), Social Politics (2020), and Journal of Family Issues (2021, together with García-de-Diego). 